\title{
ALTAS HABILIDADES/SUPERDOTAÇÃO: \\ UMA LARGA BRECHA ENTRE AS LETRAS DO PAPEL E O CHÃO DA ESCOLA
}

Susana Graciela Pérez Barrera Pérez.*

RESUMO: O artigo apresenta o histórico de encontros e desencontros entre as diversas legislações, normas, políticas públicas de Educação Especial e demais documentos educacionais brasileiros relacionados às Altas Habilidades/Superdotação e seus reflexos positivos e negativos nas práticas educacionais desde o início do século XIX até o ano 2021.

PALAVRAS-CHAVE: Altas habilidades/superdotação. Política pública. Legislação educacional.

\section{HIGH ABILITIES/GIFTEDNESS: A LARGE GAP BETWEEN THE WORDS ON THE PAPER} AND THE SCHOOL FLOOR

\begin{abstract}
The paper presents the history of encounters and mismatches among the Special Education different laws, rules, public policies and other Brazilian documents related to High Abilities/Giftedness and their positive and negative reflexes on educational practices between the beginning of the $19^{\text {th }}$. century and 2021.
\end{abstract}

KEYWORDS: High abilities/giftedness. Public policy. Educational laws.

\footnotetext{
* Doutora em Educação (PUC-RS), pós-doutorado em Educação (UFSM), líder do Grupo de Investigación en Altas Habilidades/ Superdotación (GIAHSD), Coordenadora da Unidade de Pesquisa e da Especialización en Educación Inclusiva para Estudiantes com Altas Habilidades/Superdotación da Facultad de Ciencias de la Educación, da Universidad de la Empresa, membro do Sistema Nacional de Investigadores, Montevidéu, Uruguai. sperezbarrera@ude.edu.uy. ORCID: 00000003-1449-469X.
} 


\section{Era uma vez...}

Era uma vez um país que ainda não tinha atendimento educacional para seus estudantes com Altas Habilidades/Superdotação (AH/SD). Para os cegos, já existia o Instituto dos Meninos Cegos e, para os surdos, o Instituto dos Surdos Mudos, criados por Dom Pedro II, respectivamente, em 1854 e 1857.

Embora as primeiras pesquisas tivessem começado muito cedo, no Instituto de Psicologia de Recife, lá por 1929, e os primeiros livros tivessem sido publicados na década de 1930 por Leoni Kaseff e Estêvão Pinto (NOVAES, 1979), ainda não havia uma política pública destinada às pessoas com AH/SD.

Prefaciando a Pinto (1933, p. 3), Lourenço Filho já afirmava que "o problema da educação dos bem-dotados - ou seja, das crianças que, desde a escola primária, revelem aptidões excepcionaes - não se contém nas preocupações de ordem didactica. É, antes disso, e acima disso, um largo problema de natureza politica".

Embora a visão daqueles estudiosos quanto à educação dos estudantes com AH/SD tivesse como foco criar uma elite intelectual, cultural e técnica que contribuísse para o futuro do país, uma ideia que ainda persiste em alguns contextos, Pinto (1933, p. 10) clamava pela "assistência do poder público" que, segundo ele, deveria ser mediante a atribuição de bolsas de estudo, mas, fundamentalmente requeria a "reorganização estrutural da escola", porque "a escola comum tem sido a causa do desperdício de numerosas capacidades”. A segregação como forma de atender às diferenças era o modelo apregoado como mais adequado, embora, ao mesmo tempo, o autor (ibidem, p. 24) referia que "o nivelamento de todas as capacidades é tão impossível quanto o nivelamento de todas as physionomias humanas" e lembrava o que Stern (s.d., s. p.) afirmava sobre a igualdade, que "só pode consistir em oferecer a todos os homens a mesma possibilidade de desenvolver-se de acordo com os seus dotes pessoaes", um preceito consignado na nossa constituição de 1988 e que ainda não conseguimos cumprir.

Naquela época em que até a língua portuguesa era diferente, alertava-se para a importância de identificar e atender educativamente os estudantes com AH/SD, para a necessidade de uma política pública e para a existência nociva dos mitos e das crenças populares, dos quais hoje tanto falamos e que tanto atrapalham no reconhecimento, aceitação e valorização dessas pessoas.

Crianças excelentemente inteligentes e precoces sempre existiram em todos os tempos. Não constituem nenhuma novidade. Mas eram taes crianças objecto de concepções erroneas e absurdas. Os alienistas consideravam-nas puros casos pathologicos, ao passo que para o vulgo em geral se afiguram ellas entidades sobrenaturaes e inexplicaveis (PINTO, 1933, p. 15-16).

Helena Antipoff também nos falava sobre a necessidade de identificar os "bem-dotados" e do atendimento educacional que precisavam e já na década de 1940 desenvolvia atividades extracurriculares 
com estudantes da periferia do Rio de Janeiro, na Sociedade Pestalozzi, primeiro e, na Fazenda do Rosário, em Minas Gerais, depois, na década de 1960 (NOVAES, 1979).

\section{Mainstreaming: a integração que ainda não deixou nossas escolas}

Com o crescente movimento de defesa de direitos das pessoas com deficiência - particularmente, com deficiência intelectual - antes confinadas às classes especiais, na década de 1960, a segregação dá lugar à integração escolar; a chamada "mainstreaming education" leva os estudantes com necessidades educacionais especiais à escola regular, mas coloca neles a responsabilidade de se adaptarem à corrente geral, isto é, à média.

No Brasil, em 1961, a primeira Lei de Diretrizes e Bases da Educação Nacional, a Lei 4062/61, no Título X, ocupava-se da Educação dos Excepcionais. Em dois breves artigos, previa a "integração" desses diferentes, que supostamente incluíam tanto as pessoas com deficiência como as pessoas com Altas Habilidades/Superdotação, visto o uso do termo "excepcionais" para identificar tanto uns quanto outros:

Art. 88. A educação de excepcionais, deve, no que fôr possível, enquadrar-se no sistema geral de educação, a fim de integrá-los na comunidade.

Art. 89. Tôda iniciativa privada considerada eficiente pelos conselhos estaduais de educação, e relativa à educação de excepcionais, receberá dos poderes públicos tratamento especial mediante bôlsas de estudo, empréstimos e subvenções (BRASIL, 1961, p. 12).

Foi então que, em 1967, o Ministério da Educação e do Desporto põe um pouco de atenção nas pessoas com $\mathrm{AH} / \mathrm{SD}$, quando cria uma Comissão que terá como função estabelecer os critérios para a sua identificação e atendimento educacional (NOVAES, 1979).

Nas décadas de 1960 e 1970 crescem os movimentos que buscam a desinstitucionalização das pessoas com deficiência e sua participação ativa nas instituições educacionais e a Educação Especial vai se constituindo num campo habitado somente por elas. Embora os estudantes com AH/SD já fossem objeto de estudo e atendimento educacional em alguns países muitíssimos anos antes, progressivamente vão sendo excluídos, embora mencionados em normas e legislações.

A exemplo disso, a Lei 5692/71, que substitui a Lei de Diretrizes e Bases da Educação Nacional anterior (BRASIL, 1961), no seu Artigo $9^{\circ}$ estabelece o "tratamento especial" para os estudantes que: “[...] apresentem deficiências físicas ou mentais, os que se encontrem em atraso considerável quanto à idade regular de matrícula e os superdotados deverão receber tratamento especial, de acordo com as normas fixadas pelos competentes Conselhos de Educação” (BRASIL, 1971, p. 3, grifos meus). 
Apesar de não apresentar qualquer definição sobre os estudantes aos quais deve-se oferecer tal "tratamento", a lei adiantou-se ao famoso Relatório Marland (MARLAND, 1971) que, por solicitação do Congresso dos Estados Unidos, realiza um estudo sobre essa população naquele país e cuja definição a primeira nos Estados Unidos - será introduzida total ou parcialmente nas legislações brasileiras posteriores:

\begin{abstract}
As crianças superdotadas e talentosas são aquelas identificadas por pessoas profissionalmente qualificadas que, em virtude de suas habilidades destacadas, são capazes de (ter) um elevado desempenho. Essas são crianças que requerem programas e/ou serviços educacionais diferenciados além daqueles fornecidos pelo programa escolar regular para concretizar sua contribuição para si mesmos e para a sociedade.

As crianças capazes de (ter) um elevado desempenho incluem aquelas que demostram rendimento e/ou habilidade potencial em alguma das seguintes áreas, individualmente ou combinadas:

1. habilidade geral intelectual

2. aptidão acadêmica específica

3. pensamento criativo ou produtivo

4. habilidade de liderança

5. artes visuais e performáticas

6. habilidade psicomotora

Pode se supor que a utilização desses critérios para a identificação dos superdotados e talentosos abrangerá uma porcentagem mínima de 3 a 5 por cento da população escolar (MARLAND, 1971, p. 8, tradução nossa).
\end{abstract}

Embora essa definição tenha sido um marco importante por ser mais ampla que o singelo conceito de QI elevado, que infelizmente e equivocadamente ainda é utilizado como sinônimo de $\mathrm{AH} / \mathrm{SD}$ em alguns municípios e estados do Brasil, tenho minhas reservas quanto a ela por algumas razões.

Em primeiro lugar, a definição limita a "superdotação e o talento" às crianças e assim continuamos entendendo as $\mathrm{AH} / \mathrm{SD}$, durante muitos anos, somente na infância. Em segundo lugar, as seis áreas apontadas como possíveis áreas de destaque superpõem-se e podem conduzir a confusões. Como poderia a habilidade geral intelectual, identificada com o antigo conceito de "fator g" e que teoricamente envolveria as inteligências linguística e lógico-matemática, ser excludente da aptidão acadêmica específica, do pensamento criativo ou produtivo, da habilidade de liderança, das artes visuais e performáticas, ou mesmo da habilidade psicomotora? É possível ter um desempenho acadêmico específico, sem a linguagem ou o raciocínio lógico-matemático? Pode uma criança criativa não ter "uma habilidade intelectual"? Um líder, um ator ou um cantor pode demostrar seu "talento" sem a linguagem? Poderia um desenhista, um pintor, um músico, um atleta ou um desportista não utilizar de forma destacada a inteligência lógico-matemática?

É importante observar uma afirmação desse relatório que não tem sido mencionada quando se faz referência a esse estudo e que deveria ser considerada: 
A evidencia de habilidades de superdotação e talento podem ser determinadas por uma multiplicidade de formas. Esses procedimentos incluem medidas objetivas e medidas avaliativas profissionais que são componentes essenciais da identificação.

As pessoas profissionalmente qualificadas incluem indivíduos tais como professores, administradores, psicólogos escolares, orientadores, especialistas em currículo, artistas, músicos e outros com treinamento especial que também sejam qualificados para avaliar as competências especiais dos estudantes (MARLAND, 1971, p. 9).

Novaes (1979) referia que o Parecer no 255/72, do Conselho Federal de Educação (CFE) estabelecia que os estudantes de ensino fundamental e médio poderiam avançar sem barreiras rígidas e de acordo com seus “interesses, aptidões e ritmos de aprendizagem”, adotando-se a matrícula por disciplinas, a compactação dos anos escolares e a dispensa da frequência do estudante que apresentasse aproveitamento excepcional.

No mesmo ano, outro Parecer daquele Conselho - o $n^{\circ} 436 / 72$ - permitia que o estudante superdotado identificado antes da inscrição no vestibular, fosse matriculado no ensino superior, tendo até dois anos para concluir o ensino médio (BRASIL, 1995a).

O Parecer 681/73, no qual se atribuía ao CFE a responsabilidade pela definição do conceito de superdotação e dos critérios de identificação (BRASIL, 1995a) ainda permanece cumprido parcialmente. Se bem o Centro Nacional de Educação Especial (CENESP), criado em julho de 1973, destaca em suas Diretrizes básicas de ação uma política para essa população, a sua justificativa arrasta uma ideia de cunho nacionalista que apoiando-se no preceito de que "todas as pessoas devem ter oportunidade de desenvolver ao máximo as potencialidades próprias" sugere que os superdotados, “[...] atendidos adequadamente, irão formar elites mais aptas nos vários campos da reflexão e da práxis - para darem continuidade e expandirem o desenvolvimento brasileiro, dinamizarem e inovarem a sociedade" (NOVAES, 1979, p. 84-85).

Entre 1973 e 1977, o CENESP organiza e apoia encontros e seminários de especialistas e, no mesmo ano em que foi transformado na Secretaria de Educação Especial (SEESP), enuncia a Portaria n ${ }^{\circ}$ 69 de agosto de 1986, que apresenta uma definição muito semelhante à definição do Relatório Marland acima citado, reiterada nos documentos e normativas da Educação Especial do MEC até os nossos dias:

Superdotados: educandos que apresentam notável desempenho e/ou elevada potencialidade nos seguintes aspectos, isolados ou combinados: capacidade intelectual, aptidão académica, pensamento criador, capacidade de liderança, talento especial para artes, habilidades psicomotoras, necessitando atendimento educacional especializado (BRASIL, 1995a, p. 11).

No ano seguinte, sob a batuta de Arnaldo Niskier, então membro do CFE, uma poderosa equipe de especialistas, dentre eles o Prof. João Bina Machado, primeiro presidente da Associação Nacional de Superdotados (1978) e as saudosas Maria Helena Novaes e Sara Couto César, elaboram um Relatório que culmina na Portaria $N^{\circ} 711 / 87$. Essa Portaria propõe que o CFE efetive a determinação da Portaria 
681/73, que seja retomada a definição de Superdotação da Portaria $N^{\circ} 69$ do CENESP, a descentralização da competência para declarar a superdotação, recomenda procedimentos de identificação, modalidades de atendimento e a formação de recursos humanos, assim como o estímulo aos estudos e pesquisas por parte das instituições de ensino superior. Propõe também, entre outras sugestões, que se constitua uma Coordenadoria Nacional dentro da SEESP, o envolvimento das Secretarias e Conselhos de Educação dos Estados e que se estimule a participação da família, da escola, das empresas e da comunidade para criar oportunidades de desenvolvimento para os superdotados (CFE, 1987). Merecem destaque as importantes recomendações de adotar, o mais cedo possível, procedimentos de identificação multidisciplinares que englobem a "avaliação de professores, pais e especialistas" e o incentivo a diversas alternativas de atendimento, abrangendo aceleração e diferentes formas de enriquecimento e orientação (BRASIL, 1987, p. 4).

\section{Rumo à inclusão, mas ainda não}

$\mathrm{Na}$ década de 1990 começa a se delinear o novo paradigma da inclusão, tentando suplantar a integração, que previa apenas a frequência à escola regular e a adaptação dos estudantes ao sistema educativo regular. Infelizmente, tanto a integração quanto a inclusão tinham e continuam tendo como alvo somente as pessoas com deficiência, apesar de que os destinatários tanto de uma modalidade quanto da outra fossem e sejam as pessoas com deficiência e as pessoas com AH/SD que, juntos, formam o grupo dos estudantes com necessidades educacionais especiais (NEE) que requerem atendimento educacional especializado (AEE).

A Declaração Mundial de "Educação para todos" (1990); a Declaração de Nova Delhi (1993), que, no Brasil, embasa o Plano Decenal de Educação para todos (1993), obrigam, de certa forma, a pensar na ideia de inclusão daqueles estudantes mais vulneráveis e, mais especificamente, a Declaração de Salamanca (1994), ao referir os estudantes com AH/SD como alvo da Educação Especial e afirmar que “no contexto desse Marco de Ação, o termo 'necessidades educacionais especiais' refere-se a todas as crianças e jovens cujas necessidades derivam de sua capacidade ou de suas dificuldades de aprendizagem" (UNESCO, 1994, p. 6).

Essa década fértil de declarações, normativas e legislações origina a tentativa de passagem ao novo paradigma, pelo menos nas letras do papel, embora ainda com muitas contradições conceituais que talvez por falta de aprofundamento teórico e desconhecimento da realidade do chão da escola - ainda permanecem nos documentos legais até os nossos dias.

Concordando com o Marco de Ação estabelecido em Salamanca (UNESCO, 1994), a Política Nacional de Educação Especial de 1994 especifica entre os "portadores de necessidades educativas especiais" os então chamados "portadores de altas habilidades (superdotados)" definindo-os com base no Relatório Marland de 1971, como: 
Notável desempenho e elevada potencialidade em qualquer dos seguintes aspectos isolados ou combinados:

- capacidade intelectual geral

- aptidão acadêmica específica

- pensamento criativo ou produtivo

- capacidade de liderança

- talento especial para artes

- capacidade psicomotora (BRASIL, 1994, p. 13).

Em 1995, a SEESP/MEC publica, com o apoio da Unesco, a Série Diretrizes, na qual inclui a reedição dos Subsídios para organização e funcionamento de serviços de Educação Especial - Área de Altas Habilidades, elaborado pelo CENESP e as Diretrizes gerais para o atendimento educacional aos alunos portadores de Altas Habilidades/Superdotação e talentos.

As Diretrizes (BRASIL, 1995a, p. 13) seguem a Teoria de Superdotação dos Três Anéis (RENZULLI, 1978), que a define os comportamentos de superdotação como a intersecção de três conjuntos de traços - habilidade acima da média, comprometimento com a tarefa e criatividade. $\mathrm{Na}$ definição utilizada no documento, "Altas Habilidades referem-se aos comportamentos observados e/ou relatados que confirmem a expressão de 'traços consistentemente superiores' em relação a uma média (por exemplo: idade, produção ou série escolar) em qualquer campo do saber ou do fazer", explicitando que esses traços devem ser consistentes e apresentarem-se com suficiente frequência e duração como para que possam registrar-se em épocas diferentes e situações semelhantes. Como na definição de Renzulli, reconhece que o "envolvimento com a tarefa" e a criatividade podem se expressar "em diferentes formas: gestual, plástica, teatral, matemática ou musical, entre outras”, já destacando a associação da habilidade acima da média às Inteligências Múltiplas (GARDNER, 2011) e a presença desses comportamentos em qualquer grupo social.

Entretanto, imediatamente depois, o documento (BRASIL, 1995a, p. 14) apresenta uma representação gráfica intitulada "Segundo o Modelo Triádico da Superdotação (Renzulli)" (Figura 1), cometendo dois erros. O primeiro é que Renzulli denomina "Modelo Triádico de Enriquecimento" (não, da Superdotação) a representação gráfica das atividades propostas para o atendimento educacional dos estudantes com AH/SD e o segundo é que a figura não correspondente à representação gráfica original da Teoria dos Três Anéis (Figura 2), mas é uma mistura dela com o Modelo Multifatorial de Superdotação de Mönks, de 1986 (Figura 3).

Figura 1- Representação gráfica equivocada da Teoria dos Três anéis

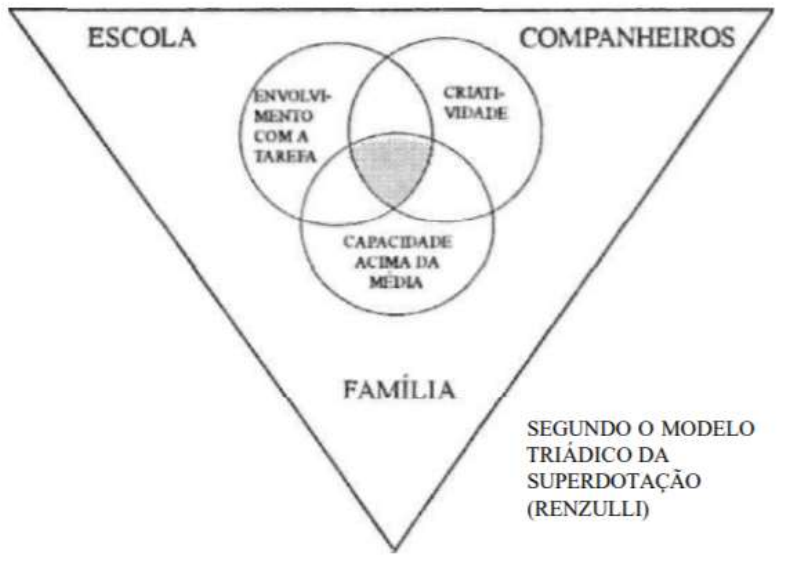


Fonte: Brasil (1995a, p. 14)

Figura 1 - Representação gráfica da Teoria da dos Três Anéis (Traduzido e adaptado de Renzulli, 1978)

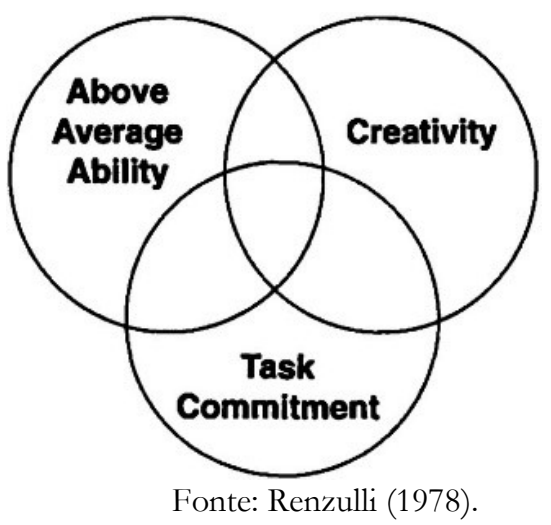

Figura 3 - Modelo multifatorial de superdotação (MONKS, 1986)

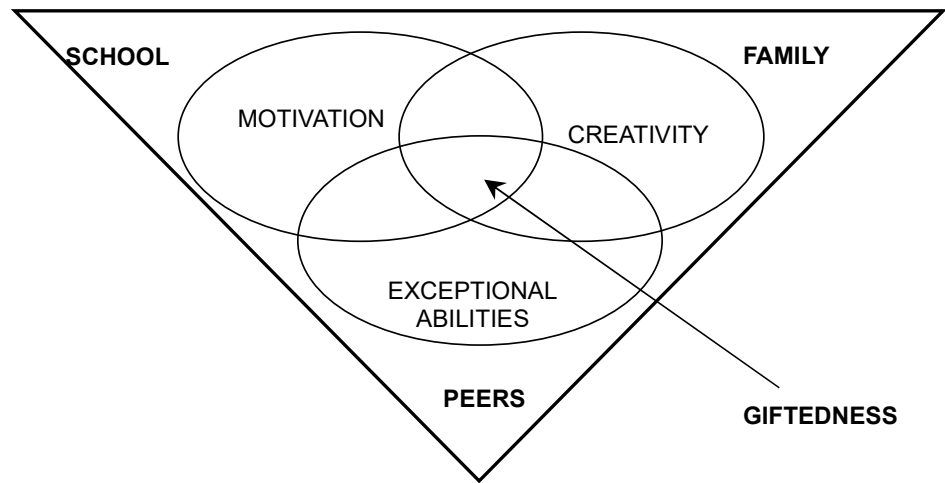

Fonte: (MONKS; KATZKO, 2005, p. 191)

Logo em seguida, o documento apresenta seis "tipos de superdotação" como sendo parte da "conceituação adotada pelo MEC": intelectual, social, acadêmico, criativo, psicomotricinestésico e dos talentos especiais (BRASIL, 1995a, p. 14-15). No documento Subsídios para Organização e Funcionamento de Serviços de Educação Especial (BRASIL, 1995b), publicado na mesma Série Diretrizes e no mesmo ano, incorpora-se outra conceituação e outras características em cada tipo, como veremos mais adiante.

Para aumentar a confusão do leitor, em seguida, refere-se às habilidades do modelo de talentos múltiplos de Taylor, de 1976: capacidade acadêmica, criatividade, relacionamento humano planejamento, comunicação, previsão, tomada de decisão, implementação e discernimento de oportunidades (BRASIL, 1995a). A caracterização dos tipos de "educandos portadores de altas habilidades/superdotados" inicia referindo que: 
além de expressivo nível de desempenho na área de superdotação. Registram-se, em muitos casos, a PRECOCIDADE do aparecimento das HABILIDADES e a resistência dos indivíduos aos obstáculos e frustrações existentes no seu desenvolvimento. Crianças e jovens ainda estão no processo de desenvolvimento e muitas vezes, apesar de sua precocidade, não efetivam todo o seu potencial. Nessas faixas etárias, geralmente, apenas começam a se evidenciar suas ALTAS HABILIDADES. Daí serem considerados PORTADORES DE ALTAS HABILIDADES/SUPERDOTADOS, e não ainda superdotados (grifos no original) (BRASIL, 1995b, p. 17).

No parágrafo seguinte, o documento apresenta a definição da Política Nacional de Educação Especial de 1994 que, como "portadores de altas habilidades/superdotação", entende exatamente os mesmos indivíduos definidos pelo Relatório Marland (1971), como já citado anteriormente. Depois, descreve as características dos seis tipos já referidos nas Diretrizes Gerais (BRASIL, 1995a), com uma diferença na terminologia e no tipo psicomotricinestésico que, nos Subsídios, denomina-se apenas psicomotor.

Acredito que, nessa "reedição desta publicação, enriquecida e atualizada" (BRASIL, 1995b, p. 2), os tipos psicomotor e de talentos especiais foram um acréscimo aos tipos da edição original, de 1986, (que, infelizmente, não está disponível), visto que Duarte (1993) refere aquela edição, mencionando as mesmas características de quatro dos seis tipos apresentados nas Diretrizes Gerais (BRASIL, 1995a): intelectual, acadêmico, criativo e social (Quadro 1), e com algumas pequenas variantes em relação à reedição de 1995.

Quadro 1- Características dos diferentes tipos de Altas Habilidades/Superdotação apresentados nas edições de 1986 (apud DUARTE, 1993) e de 1995 do documento Subsídios para Organização e Funcionamento de Serviços de Educação Especial e o das as Diretrizes Gerais para o Atendimento Educacional aos Alunos Portadores de Altas Habilidades/Superdotação

\begin{tabular}{|c|c|c|}
\hline $\begin{array}{l}\text { SUBSÍDIOS } 1986 \text { (apud DUARTE, } \\
\text { 1993, p. 20-21) }\end{array}$ & $\begin{array}{l}\text { DIRETRIZES GERAIS } \\
\text { (BRASIL1995a, p.14) }\end{array}$ & SUBSÍDIOS (1995b, p. 17-18) \\
\hline \multicolumn{3}{|c|}{ Tipo intelectual } \\
\hline $\begin{array}{llll}\begin{array}{l}\text { Flexibilidade } \\
\text { pensamento }\end{array} & \text { fluência } & \\
\end{array}$ & $\begin{array}{l}\text { Flexibilidade, independência e } \\
\text { fluência de pensamento }\end{array}$ & Flexibilidade e fluência de pensamento \\
\hline Independência de pensamento & & Independência de pensamento \\
\hline $\begin{array}{l}\text { Capacidade de pensamento abstrato } \\
\text { para fazer associações }\end{array}$ & & $\begin{array}{l}\text { Capacidade de pensamento abstrato para fazer } \\
\text { associações }\end{array}$ \\
\hline Produção ideativa & Produção intelectual & Produção ideativa \\
\hline Rapidez de pensamento & & Rapidez de pensamento \\
\hline Julgamento crítico & Julgamento crítico & Julgamento crítico \\
\hline Elevada compreensão e memória & & Compreensão e memória elevadas \\
\hline $\begin{array}{l}\text { Capacidade de resolver e lidar com } \\
\text { problemas }\end{array}$ & $\begin{array}{l}\text { Habilidade para resolver } \\
\text { problemas }\end{array}$ & Capacidade de resolver e lidar com problemas \\
\hline \multicolumn{3}{|c|}{ Tipo social } \\
\hline Capacidade de liderança & Capacidade de liderança & Capacidade de liderança \\
\hline Sensibilidade interpessoal & Sensibilidade interpessoal & Sensibilidade interpessoal \\
\hline Atitude cooperativa & Atitude cooperativa & Atitude cooperativa \\
\hline \multirow[t]{3}{*}{ Sociabilidade expressiva } & Sociabilidade expressiva & Sociabilidade expressiva \\
\hline & Poder de persuasão & Alto poder de persuasão \\
\hline & Influência no grupo & Alto poder de influência no grupo \\
\hline
\end{tabular}




\begin{tabular}{|c|c|c|}
\hline $\begin{array}{l}\text { Habilidade de trato com pessoas } \\
\text { diversas e grupos para estabelecer } \\
\text { relações musicais (sic) }\end{array}$ & & $\begin{array}{l}\text { Habilidade de trato com pessoas diversas e } \\
\text { grupos }\end{array}$ \\
\hline & & Percepção acurada das situações de grupo \\
\hline & & $\begin{array}{l}\text { Capacidade para resolver situações sociais } \\
\text { complexas }\end{array}$ \\
\hline \multicolumn{3}{|c|}{ Tipo acadêmico } \\
\hline Aptidão acadêmica específica & & Aptidão acadêmica específica \\
\hline Atenção & Capacidade de atenção & Atenção \\
\hline Concentração & Concentração & Concentração \\
\hline Rapidez de aprendizagem & & Rapidez de aprendizagem \\
\hline Boa memória & Memória & Boa memória \\
\hline $\begin{array}{l}\text { Interesse e motivação pelas tarefas } \\
\text { académicas de seu interesse }\end{array}$ & $\begin{array}{l}\text { Interesse e motivação pelas } \\
\text { tarefas académicas }\end{array}$ & $\begin{array}{l}\text { Gosto e motivação pelas tarefas académicas de } \\
\text { seu interesse }\end{array}$ \\
\hline $\begin{array}{l}\text { Habilidade para avaliar, sintetizar e } \\
\text { organizar o conhecimento }\end{array}$ & & $\begin{array}{l}\text { Habilidade para avaliar, sintetizar e organizar o } \\
\text { conhecimento }\end{array}$ \\
\hline Capacidade de produção acadêmica & Capacidade de produção & Capacidade de produção acadêmica \\
\hline \multicolumn{3}{|c|}{ Tipo criativo } \\
\hline Imaginação & & Imaginação \\
\hline $\begin{array}{l}\text { Capacidade para resolver problemas } \\
\text { de forma diferente e inovadora }\end{array}$ & $\begin{array}{llr}\text { Capacidade } & \text { de encontrar } \\
\text { soluções } & \text { diferentes } \\
\text { inovadoras } & & \\
\end{array}$ & $\begin{array}{l}\text { Capacidade para resolver problemas de forma } \\
\text { diferente e inovadora }\end{array}$ \\
\hline Facilidade de autoexpressão & Facilidade de autoexpressão & Facilidade de autoexpressão \\
\hline Fluência & Fluência & Fluência \\
\hline $\begin{array}{l}\text { Sensibilidade para as situações } \\
\text { ambientais }\end{array}$ & & Sensibilidade para as situações ambientais \\
\hline $\begin{array}{l}\text { Reações e produções diferentes, às } \\
\text { vezes extravagantes }\end{array}$ & & $\begin{array}{l}\text { Reações e produções diferentes, às vezes } \\
\text { extravagantes }\end{array}$ \\
\hline $\begin{array}{l}\text { Sentimento de desafio diante da } \\
\text { desordem de todos }\end{array}$ & & $\begin{array}{l}\text { Sentimento de desafio diante da desordem de } \\
\text { fatos }\end{array}$ \\
\hline Originalidade & Originalidade & Originalidade \\
\hline \multirow[t]{9}{*}{ Flexibilidade } & Flexibilidade & Flexibilidade \\
\hline & Tipo psicomotricinestésico & $\begin{array}{c}\text { Tipo psicomotor } \\
\end{array}$ \\
\hline & $\begin{array}{lcr}\begin{array}{l}\text { Habilidade e } \\
\text { atividades } \\
\text { psicomotoras }\end{array} & \text { físicas } & \text { eor } \\
\text { e } & \\
\end{array}$ & $\begin{array}{l}\text { Habilidade e interesse por atividades } \\
\text { psicomotoras }\end{array}$ \\
\hline & Agilidade & Agilidade de movimentos \\
\hline & Força e resistência & Força e resistência \\
\hline & $\begin{array}{l}\text { Controle e coordenação } \\
\text { motora }\end{array}$ & Controle e coordenação motora \\
\hline & & Desempenho fora do comum em velocidade \\
\hline & Tipo talentos especiais & $\begin{array}{c}\text { Tipo talento especial } \\
\end{array}$ \\
\hline & $\begin{array}{l}\text { Destaque nas artes plásticas, } \\
\text { musicais, literárias e } \\
\text { dramáticas }\end{array}$ & $\begin{array}{l}\text { Destaque nas artes plásticas, musicais, } \\
\text { dramáticas, literárias ou técnicas, evidenciando } \\
\text { habilidades especiais para essas atividades e alto } \\
\text { desempenho }\end{array}$ \\
\hline
\end{tabular}

Fonte: Elaborado pela autora (2021).

Seria difícil de imaginar a capacidade especial e o alto desempenho nas artes plásticas, musicais, literárias e dramáticas (tipo talento especial) sem a capacidade de encontrar soluções diferentes e inovadoras, a facilidade de autoexpressão ou a originalidade, a imaginação, a flexibilidade e a fluência, a habilidade para avaliar, sintetizar e organizar o conhecimento, a memória, a concentração, a atenção, a capacidade de resolver e lidar com problemas, a capacidade de pensamento abstrato para fazer associações, a independência de pensamento, entre outras, características atribuídas a outros tipos. A atenção e concentração, a rapidez de aprendizagem e a boa memória são características requeridas para 
o desempenho do tipo psicomotricinestésico ou do tipo talento especial, mas definidas como elementos do tipo acadêmico, assim como também são necessárias muitas características do tipo criativo. Todas as características definidas para o tipo social são necessárias para o tipo psicomotricinestésico, particularmente quando se trata de esportes coletivos, por exemplo, ou para o tipo talentos especiais, em orquestras, bandas ou outras associações artísticas.

Em contrapartida, os dois documentos (BRASIL, 1995a e 1995b) diferem um pouco quanto ao procedimento de identificação. Nas Diretrizes, entende-se como um processo dinâmico e contínuo que deve considerar as informações de várias fontes e sugere-se que seja feito "principalmente por meio de observação sistemática do comportamento e do desempenho do aluno, sempre que possível com foco em seu dia-a-dia, como passeios, no recreio, em jornadas e atividades de lazer" (grifos no original), como uma forma de verificar a intensidade, a frequência e a consistência dos traços peculiares dos estudantes com $\mathrm{AH} / \mathrm{SD}$ ao longo do desenvolvimento que não pode decorrer "somente do acompanhamento de seu rendimento escolar nem do resultado de testes de inteligência” (BRASIL, 1995a, p. 17).

Do processo de identificação deve fazer parte o maior número possível de dados, informações e pontos de vista, desde aquele do diretor da escola aos dos professores, companheiros e familiares do aluno. [...] Existem numerosos modelos de inventário e de questionário, padronizados ou não, que podem ser utilizados nas diferentes etapas da identificação. [...]. Deve-se considerar também a possibilidade de se levantar esse perfil sem se contar com técnicos, especialistas e equipes de avaliação. Nesse caso, o professor assume mais um grande papel: a avaliação minuciosa, detalhada, completa e real de seu aluno (BRASIL, 1995a, p. 18-19).

Já na reedição dos Subsídios, percebe-se um pensamento ambivalente. Por um lado, à diferença das Diretrizes (BRASIL, 1995a), o documento reflete uma visão clínica ao recomendar que "deverão ser utilizados para seu diagnóstico testes individuais e/ou coletivos que ofereçam garantia de rigor científico e adequabilidade, e deverão ser aplicados, por profissional especificamente preparado, diversos meios e recursos nesse processo" referindo "o pressuposto de que o portador de altas habilidades/superdotado se destaca e demonstra potencialidade elevada em relação ao seu grupo e evidencia significativo desempenho na área de sua dotação" (BRASIL, 1995b, p. 23-24). O papel fundamental do professor, destacado nas Diretrizes, passa a ser coadjuvante nesse documento, indicando a importância da "opinião do professor" na indicação dos melhores em sala de aula em diferentes aspectos que podem ser constatados no cotidiano escolar e em outros um tanto descabidos, como aqueles alunos que "têm pais famosos e de destaque artístico ou científico" ou que "são considerados inteligentes, mas emocionalmente perturbados" (Ibidem, p. 26). Por outro lado, apresenta uma tabela na qual descreve as limitações, as observações do professor e dos procedimentos de identificação que recomenda, como os testes individuais e coletivos de inteligência, baterias de testes de aptidões diferenciadas, os testes de rendimento, desempenho escolar e de criatividade.

Ao contrário do que apregoam as Diretrizes (BRASIL, 1995a), o claro enfoque no rendimento escolar do documento reeditado dos Subsídios fica evidenciado ao referir que "o portador de altas 
habilidades/superdotado pode ser afastado dos programas se não estiver tendo aproveitamento adequado nem estiver obtendo ganhos pessoais de acordo com o nível de motivação e desempenho apresentado nas medidas de avaliação" (Ibidem, p. 26).

Apesar dessas contradições em dois documentos que deveriam coincidir, os Subsídios (BRASIL, 1995b) dedicam uma seção bastante extensa às alternativas de atendimento educacional, explanando as diferentes possibilidades de programas de enriquecimento, aceleração, atividades especiais, agrupamento especial, atendimento específico para o desenvolvimento de talentos (somente as áreas artísticas, industriais, etc.), atendimento interescolar, aprendizagem diferenciada, orientação individual ou grupal, uso de serviços ou centros de recursos didáticos e protótipos. Essas alternativas também se superpõem e propõem atividades muito similares entre os diferentes "programas", mas serviram para mostrar uma variedade delas em uma época em que a pesquisa e o atendimento aos estudantes com AH/SD ainda eram quase inexistentes no Brasil.

Ainda no paradigma da integração, embora em época de fortalecimento da inclusão, a Lei de Diretrizes e Bases da Educação Nacional - LDB (BRASIL, 2021a) postula o capítulo sobre a Educação Especial no qual os estudantes com AH/SD aparecem nomeados como parte do seu público-alvo e nesse mesmo ano começam a ser contabilizados no Censo Escolar em números que variam de forma inexplicável, como se observa no quadro 2, e que refletem a carência de políticas públicas para esses educandos.

\section{Quadro 2 - Evolução das matrículas de estudantes com AH/SD na Educação Básica e percentual de variação anual (1996-2020)}

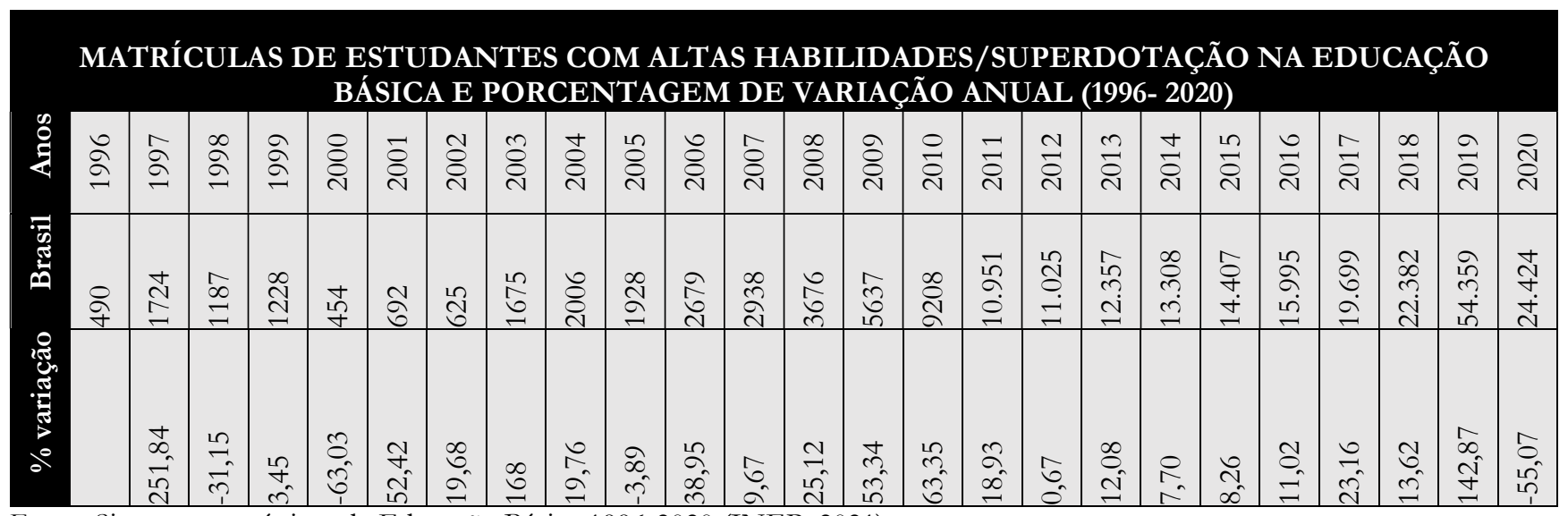

Fonte: Sinopses estatísticas da Educação Básica 1996-2020 (INEP, 2021)

Os altibaixos verificados no Quadro 2 mostram momentos significativos na mudança das normativas e outras variáveis que não podem ser explicadas muito claramente. O aumento significativo de 1996 a 1997 $(251,84 \%)$ certamente reflete a introdução dessa população na LDB, assim como o de 2006 (38,95\%) mostra a importância que teve a implementação da política nacional para o atendimento aos alunos com AH/SD, com a implantação dos Núcleos de Atividades em Altas Habilidades/Superdotação (NAAH/S), 
em 2005, que decai à medida que os recursos e as formações diminuem. O número do ano 2000 (-63,03\%) talvez possa se explicar pelas novas orientações para o registro do estudante quando estiver em atendimento específico, o que foi pouco compreendido naquela época.

O aumento significativo de 2003 (168\%) certamente reflete a aprovação das Diretrizes Nacionais para a Educação Especial na Educação Básica (BRASIL, 2001), que consideram o atendimento educacional aos alunos com AH/SD; o de 2009 (53,34\%), o Decreto 6371 de 2008 e o de 2010 (63,35\%), o Parecer N ${ }^{\circ} 13$ e a Resolução N 4 de 2009 que estabelecem as Normas Operacionais para o AEE, também para os estudantes com AH/SD, mas é difícil explicar a significativa queda nos percentuais em 1998 (-31,15), 2005 (-3,88\%), os aumentos significativos de 2001 (52,42\%), 2017 (23,16\%) e 2019 $(142,87 \%)$ ou a brusca queda em 2020 (-55,07\%) que não têm uma explicação plausível. Porém, o que esses percentuais mostram, de forma clara e evidente, é que temos um déficit no atendimento educacional especializado e na própria identificação desses alunos que - considerando ainda as estimativas mais conservadoras -beira os 99\%, visto que, em 2020, o número de estudantes com AH/SD deveria ser, no mínimo, de 2,3 milhões. Isso, se considerarmos as matrículas globais, porque se analisarmos os percentuais por município, o mais comum é encontrar um redondo zero no lugar onde deveria ser declarado o número de estudantes com AH/SD.

No ensino superior, a determinação $\int 2^{\circ}$ do artigo 47 da LDB que permite que "os alunos que tenham extraordinário aproveitamento nos estudos, demonstrado por meio de provas e outros instrumentos de avaliação específicos, aplicados por banca examinadora especial” (BRASIL, 2021a, p. 21) possam abreviar a duração de seus estudos também raramente é implementada pelas universidades que, da mesma forma, não identificam nem atendem educacionalmente a seus alunos com AH/SD.

Aplicando a mesma estimativa conservadora de 5\% ao número de estudantes matriculados no ano de 2019, último registro disponível, o número de estudantes com AH/SD deveria superar os 430,000. Entretanto, o número registrado (1.551) indica que há, como na Educação Básica, um déficit de identificação e atendimento semelhante. O Quadro 3 também reflete variações inexplicáveis, entre o ano 2011, quando começou o registro desses alunos no censo escolar e o ano 2019, havendo aumentos como o que se verifica no ano de $2014(289,60 \%)$ ou valores percentuais negativos importantes, como o registrado no ano de $2016(75 \%)$.

\section{Quadro 3 - Evolução das matrículas de estudantes com AH/SD no ensino superior e variação anual (2011-2019)}

\begin{tabular}{|c|c|c|c|c|c|c|c|c|c|}
\hline \multicolumn{10}{|c|}{$\begin{array}{l}\text { MATRÍCULAS DE ESTUDANTES COM ALTAS HABILIDADES/SUPERDOTAÇÃO NA EDUCAÇÃO } \\
\text { SUPERIOR E PORCENTAGEM DE VARIAÇÃO ANUAL (1996- 2020) }\end{array}$} \\
\hline Anos & 2011 & 2012 & 2013 & 2014 & 2015 & 2016 & 2017 & 2018 & 2019 \\
\hline Matrículas & 953 & 1.085 & 1.087 & 4.235 & 4.808 & 1.202 & 1.067 & 1.486 & 1.551 \\
\hline \% variação & & 13,86 & 0,18 & 289,60 & 13,53 & $-75,00$ & $-11,23$ & 39,36 & 4,38 \\
\hline
\end{tabular}




\section{Avanço e retrocessos do flamante século}

Em 2001, o Parecer N 17 (BRASIL, 2001a) estabelece as bases para as Diretrizes Nacionais para a Educação Especial na Educação Básica que definem como os sistemas de ensino devem se organizar para atender os estudantes com NEE que são resumidas nos 22 artigos que constituem a Resolução $n^{\circ}$ 2/2001, aprovada pela Câmara de Educação Básica do CNE.

O Parecer, que apresenta a Educação Especial como modalidade de ensino transversal a todos os níveis, etapas e modalidades da Educação, reconhece os estudantes com AH/SD como um segmento da comunidade discriminado e excluído do sistema educacional que: “[...] devido a necessidades e motivações específicas - incluindo a não aceitação da rigidez curricular e de aspectos do cotidiano escolar - são tidos por muito como trabalhosos e indisciplinados, deixando de receber os serviços especiais que necessitam, como por exemplo o enriquecimento e aprofundamento curricular" (BRASIL, 2001a, p. 19).

No mesmo documento, apresenta-se uma definição das AH/SD um pouco mais aprimorada que nos documentos legais anteriores, que infelizmente fica truncada na Resolução 2, a qual replica apenas as primeiras linhas, grifadas a continuação, no item III, do seu Artigo 5:

Altas habilidades/superdotação, grande facilidade de aprendizagem que os leve a dominar rapidamente os conceitos, os procedimentos e as atitudes e que, por terem condições de aprofundar e enriquecer esses conteúdos, devem receber desafios suplementares em classe comum, em sala de recursos ou em outros espaços definidos pelos sistemas de ensino, inclusive para concluir, em menor tempo, a série ou etapa escolar (BRASIL, 2001a, p. 39, grifos meus).

Mais adiante, é digno de menção o trecho que especifica o que é necessário para o atendimento educacional desses alunos, esclarecendo que devem ser organizados os procedimentos de avaliação pedagógica e psicológica, prevista “a possibilidade de matrícula do aluno em série compatível com seu desempenho escolar, levando em conta, igualmente, sua maturidade socioemocional" e o cumprimento da legislação quanto ao atendimento suplementar, a aceleração e "o registro do procedimento em ata da escola e no dossiê do aluno". Além disso, no mesmo documento, afirma-se que é preciso "incluir, no histórico escolar, as especificações cabíveis", assim como "incluir o atendimento educacional ao superdotado nos projetos pedagógicos e regimentos escolares, inclusive por meio de convênios com instituições de ensino superior e outros segmentos da comunidade" (Ibidem, p. 49). Finalmente, recomenda que as escolas de Educação Básica realizem parcerias com instituições de ensino superior para identificar os alunos com AH/SD de forma que possam dar continuidade aos estudos no ensino médio e superior, incluso por meio de bolsas de estudo, prioritariamente para os alunos de baixa renda.

O Plano Nacional de Educação do mesmo ano, Lei No 10.172 (BRASIL, 2001b) refere-se à identificação desses estudantes, por meio de “observação sistemática do comportamento e do desempenho do aluno, com vistas a verificar a intensidade, a frequência e a consistência dos traços, ao longo de seu desenvolvimento" (p. 39) e a Meta $N^{\circ} 26$ da Educação Especial previa “implantar 
gradativamente, a partir do primeiro ano deste plano, programas de atendimento aos alunos com altas habilidades nas áreas artística, intelectual ou psicomotor", (p. 41, grifos meus). Entretanto, no capítulo relativo à Educação Superior, a meta 33 estimula a identificação pelas instituições de ensino superior de estudantes da Educação básica "com altas habilidades intelectuais, nos estratos de renda mais baixa, com vistas a oferecer bolsas de estudo e apoio ao prosseguimento dos estudos" e a 34 estimula a criação de programas de assistência estudantil para apoiar "os estudantes carentes que demonstrem bom desempenho acadêmico" (BRASIL, 2001b, p. 27, grifos meus). Essas parecem ser todas as alternativas de "atendimento educacional” que aquela Lei propõe.

Em 2002, representantes das antigas filiais da Associação Brasileira para Superdotados, profissionais e pais de todo o Brasil se reúnem em Espírito Santo e depois em Lavras para fundar o Conselho Brasileiro para Superdotação (ConBraSD). Depois do primeiro encontro nacional, em Brasília, em 2003 e, a partir de 2004, a instituição tem realizado congressos nacionais a cada dois, e internacionais a cada quatro anos.

O grande avanço no atendimento aos estudantes com AH/SD, o qual tive a oportunidade de presenciar, acontece no ano de 2005, quando a pressão das instituições de apoio, das famílias e dos profissionais da área concretiza a implementação de uma política pública para essa comunidade com a implantação dos Núcleos de Atividades em Altas Habilidades/Superdotação (NAAH/S). Foram constituídos 25 núcleos em parceria com as Secretarias Estaduais de Educação, sendo que o de Pernambuco e o de Minas Gerais ficaram vinculados às Secretaria Municipal de suas capitais. Com recursos da UNESCO, esses Núcleos, que tinham inicialmente três unidades - de apoio à família, ao professor e ao estudante -, receberiam consultores especializados durante 8 meses para formar os recursos humanos que atenderiam aos três públicos. Por diferentes razões, nem todos os NAAH/S utilizaram essa prerrogativa. Desde sua implantação, o MEC organizou quatro eventos de atualização (2005, 2011, 2017 e 2019), e para os sete restantes (2006, 2008, 2010, 2012, 2014, 2016 e 2018), o ConBraSD solicitou a parceria do MEC para que os representantes dos NAAH/S pudessem participar dos seus encontros nacionais e internacionais.

A falta de apoio das Secretarias de Educação dos Estados, a aposentadoria dos profissionais que foram formados naquela época e a falta do necessário seguimento e apoio técnico do próprio MEC reduziram muito a atuação dos NAAH/S. Os 22 que hoje restam atuam com muitíssima dificuldade, basicamente alimentados apenas pelo entusiasmo dos profissionais que neles trabalham, pelo apoio dos pais e mães dos estudantes que atendem e/ou de parcerias com instituições de suas comunidades. Ainda deve-se acrescentar que se considerarmos a estimativa mais conservadora de estudantes brasileiros, de mais de 2,3 milhões, e a localização centralizada desses NAAH/S nas capitais dos estados, é humanamente impossível que possam cumprir suas funções, mesmo que ainda existisse o número inicial deles, pois cada um deveria oferecer serviços a mais de 85.000 estudantes, seus professores e famílias. Em novembro de 2020, por uma iniciativa de alguns NAAH/S, formou-se uma Comissão Independente 
que hoje trabalha para realizar eventos que possam congregá-los e manter a necessária atualização e que forneceu os aqui apresentados ${ }^{1}$.

Por meio da Portaria $N^{\circ} 13$ de abril de 2007, o MEC dispõe a criação do Programa de Implantação de Salas de Recursos Multifuncionais. O programa distribuía equipamentos, mobiliários, materiais didáticos e pedagógicos para as salas cujo espaço físico e professor especializado deveriam ser providenciados pela escola onde seriam instaladas (BRASIL, 2010).

Apesar de que a Política Nacional de Educação Especial na Perspectiva da Educação Inclusiva (BRASIL, 2008) consultou diferentes setores envolvidos e recebeu propostas entre o ano 2006 e sua promulgação, no ano 2008 e, embora tenha incluído os estudantes com AH/SD no público-alvo da Educação Especial, mantém a definição de documentos anteriores que mesclam a definição do Relatório Marland (1971) com parte da definição de Renzulli (1978, 1986): "Estudantes com altas habilidades/superdotação demonstram potencial elevado em qualquer uma das seguintes áreas, isoladas ou combinadas: intelectual, acadêmica, liderança, psicomotricidade e artes, além de apresentar grande criatividade, envolvimento na aprendizagem e realização de tarefas em áreas de seu interesse” (BRASIL, 2008, p. 11).

Com base no Parecer N 13, a Resolução Nº 4 da Câmara de Educação Básica do CFE estabelece as Diretrizes Operacionais para o AEE e no item III do seu Artigo 4, acrescenta nova alteração na definição de estudantes com AH/SD: “aqueles que apresentam um potencial elevado e grande envolvimento com as áreas do conhecimento humano, isoladas ou combinadas: intelectual, liderança, psicomotora, artes e criatividade" (BRASIL, 2009, p. 1). Embora seja definido que o AEE deve ser oferecido nas salas de recursos multifuncionais (SRM) e os estudantes com AH/SD serem público-alvo do AEE e das salas, o Artigo $7^{\circ}$ da Resolução explicita que esses alunos "terão suas atividades de enriquecimento curricular desenvolvidas no âmbito de escolas públicas de ensino regular em interface com os núcleos de atividades para altas habilidades/superdotação e com as instituições de ensino superior e institutos voltados ao desenvolvimento e promoção da pesquisa, das artes e dos esportes" (BRASIL, 2009, p. 2).

O Decreto 7611/2011, que revoga e substitui o Decreto 6571/2008, dispõe sobre a Educação Especial e o AEE, referindo que essas atividades são suplementares à formação dos estudantes com AH/SD. O decreto é responsável pela alteração na terminologia que vinha sendo utilizada até então (Altas Habilidades/Superdotação) ao incorporar a conjunção alternativa "ou”, que traz uma ideia de incompatibilidade entre os termos "altas habilidades" e "superdotação", que frequentemente causam muitas dúvidas e infere uma diferenciação sem defini-la. O documento volta a instituir a matrícula dupla para os estudantes que recebam AEE e estejam matriculados "na rede regular de ensino, em classes

\footnotetext{
${ }^{1}$ A Comissão organizadora dos encontros dos NAAH/S e Centros de AH/SD está integrada por: Edna Santana (BA), Eliane Fraulob (MS), Ivana Lucena (RN) e Mara Souza (RJ).
} 
comuns ou em classes especiais de escolas regulares, e em escolas especiais ou especializadas” (BRASIL, 2011, p. 3).

$\mathrm{Na}$ prática, essa determinação trouxe algumas dificuldades para os NAAH/S que atendiam diretamente estudantes com $\mathrm{AH} / \mathrm{SD}$, visto que, por um lado, as escolas regulares frequentadas por esses alunos não os declaravam como tais no Censo Escolar e, por outro lado, os NAAH/S não tinham possibilidade de declará-los; portanto, a "segunda matrícula" não era distribuída.

A Nota Técnica No 46 da Diretoria de Políticas de Educação Especial (DPEE) da Secretaria de Educação Continuada, Alfabetização, Diversidade e Inclusão (SECADI) do MEC, lembra que o AEE para os estudantes com AH/SD “[...] caracteriza-se em um conjunto de atividades, visando a atender as especificidades educacionais de tais estudantes, por meio do enriquecimento curricular, de modo a promover a maximização do desenvolvimento de suas potencialidades e habilidades" e que, para isso, “o projeto político pedagógico deve prever a articulação da escola com instituições de educação superior, centros voltados para o desenvolvimento da pesquisa, das artes, dos esportes, entre outros, oportunizando a execução de projetos que atendam às necessidades educacionais específicas” desses estudantes (BRASIL, 2013, p. 1). Entretanto, mostrando o cuidado que se deve ter com a utilização da ferramenta "copiar e colar" na edição de textos, no parágrafo seguinte, logo ao lembrar a criação dos $\mathrm{NAAH} / \mathrm{S}$, em 2005, refere que "articuladamente com os professores do atendimento educacional especializado, os profissionais que atuam nos NAAH/S, apoiam a formação continuada dos professores das escolas de educação básica, a fim de identificar e atender as especificidades educacionais dos estudantes com altas habilidades ou superdotação" (BRASIL, 2013, p. 1, grifos meus). Ora, fica então a dúvida: quem oferece o AEE para os estudantes com AH/SD, as instituições de educação superior, centros de desenvolvimento de pesquisa, artes, esportes ou as salas de recursos multifuncionais? Em 2014, a mesma Diretoria publica a Nota Técnica N4, que esclarece que "não se pode considerar imprescindível a apresentação de laudo médico (diagnóstico clínico) por parte do aluno com deficiência, transtornos globais do desenvolvimento ou altas habilidades/superdotação, uma vez que o AEE se caracteriza por um atendimento pedagógico e não clínico" e que:

A exigência de diagnóstico clínico dos estudantes com deficiência, transtornos globais do desenvolvimento, altas habilidades/superdotação, para declará-lo, no Censo Escolar, público alvo da educação especial e, por conseguinte, garantir-lhes o atendimento de suas especificidades educacionais, denotaria imposição de barreiras ao seu acesso aos sistemas de ensino, configurando-se em discriminação e cerceamento de direito (BRASIL, 2014, p. 3).

Essa orientação foi, posteriormente, adicionada a todos os cadernos de orientações para preenchimento do Censo Escolar. Em 2015, a Nota Técnica $N^{\circ} 40$ trata do AEE para estudantes com AH/SD e reitera, de forma idêntica, boa parte do texto da Nota Técnica $\mathrm{N}^{\circ} 46$ de 2013, mas novamente, promove uma nova dúvida, porque enquanto na Norma $\mathrm{N}^{\circ} 46$, atribuía aos professores de educação básica a identificação e o atendimento das especificidades educacionais desses estudantes, nesse documento, refere que "àqueles estudantes identificados com altas habilidades/superdotação, cabe à 
escola ofertar o atendimento educacional especializado - AEE” (BRASIL, 2015a, p. 2), mas não especifica os responsáveis pela identificação.

A Lei 13.234 de 2015 acrescenta ao Artigo $9^{\circ}$ da LDBEN o item IV-A que incumbe à União, juntamente com os Estados, o Distrito Federal e os municípios o estabelecimento das “diretrizes e procedimentos para identificação, cadastramento e atendimento, na educação básica e na educação superior, de alunos com altas habilidades ou superdotação" (BRASIL, 2015b, p. 4), o que certamente, seis anos depois, ainda está por acontecer.

Essa mesma lei também inclui um novo artigo (59-A) que atribui ao "poder público" a instituição de um "cadastro nacional de alunos com altas habilidades ou superdotação matriculados na educação básica e na educação superior a fim de fomentar a execução de políticas públicas destinadas ao desenvolvimento pleno das potencialidades desse alunado" (BRASIL, 2021a, p. 24). Ora, o Censo Escolar da Educação Básica e o da Educação Superior, implementados pelo Instituto Nacional de Estudos e Pesquisas Anísio Teixeira (INEP), são instrumentos de coleta das informações de todos os níveis e etapas da Educação, inclusive da Educação Especial, registrando, nessa modalidade, as matrículas dos estudantes com AH/SD em todos os municípios brasileiros.

O Censo Escolar é obrigatório, normatizado, com prazos, responsáveis e responsabilidades determinadas, seus procedimentos de coleta de dados também são definidos pelo INEP e sua finalidade é permitir a compreensão da situação educacional do país e "acompanhar a efetividade das políticas públicas". Essas competências do Censo Escolar, sua abrangência e finalidade, já definidas há 25 anos parecem coincidir com o que postula a lei 13.234 e soa parecido com aquela expressão popular: "chover no molhado".

No Parágrafo Único do Artigo 59-A, o legislador deixa ao sabor do "regulamento" tudo o que deveria ficar claramente definido:

A identificação precoce de alunos com altas habilidades ou superdotação, os critérios e procedimentos para inclusão no cadastro referido no caput deste artigo, as entidades responsáveis pelo cadastramento, os mecanismos de acesso aos dados do cadastro e as políticas de desenvolvimento das potencialidades do alunado de que trata o caput serão definidos em regulamento (BRASIL, 2021a, p. 24).

As minhas reservas quanto a essa lei, que não parece ter sido elaborada por alguém com muito conhecimento do tema e nem da Educação brasileira como um todo também se referem a algumas imprecisões mais. Por exemplo, o que o legislador entende por "poder público", a quem responsabiliza pela instituição do cadastro, visto que o poder público é o conjunto de órgãos com autoridade para desempenhar as funções estatais e está formado pelos clássicos três poderes: Legislativo, Executivo e Judiciário. Qual deles será o responsável por instituir o cadastro nacional?

Outra dúvida se refere a quem seria responsável pela "identificação precoce dos alunos com altas habilidades ou superdotação" na Educação, sem a devida formação para isso e, principalmente, sem uma definição clara das AH/SD que, se já era um tanto incompleta e confusa nas normas anteriores, agora 
também propõe uma dicotomia que a deixa ainda mais inextrincável. Provavelmente não haja um possível esclarecimento dessas dúvidas, que também são as daqueles e daquelas que executam cotidianamente a educação brasileira.

Em 2020, a Resolução 15 do MEC, "dispõe sobre a destinação de recursos financeiros para equipar salas de recursos multifuncionais e bilíngues de surdos, destinadas ao atendimento educacional especializado" (BRASIL, 2020a, p. 91). A sua redação, bastante confusa, tem o objetivo de destinar recursos financeiros às "escolas pré-selecionadas pela Secretaria de Modalidades Especializadas de Educação do Ministério da Educação - SEMESP/MEC e ratificadas pelas secretarias de educação dos municípios, estados e do Distrito Federal às quais se vinculam, de acordo com os critérios de priorização do Programa Escola Acessível” "para fins de promoção da acessibilidade das salas de recursos multifuncionais específicas ou bilíngues de surdos” (IBIDEM). O valor do repasse seria, de acordo com o número de alunos, entre 20 mil reais para as escolas que atendam até 30 alunos e 45 mil para aquelas com mais de 80 alunos. Isto é, em média, o valor do repasse não chega a $\mathrm{R} \$ 50,00$ por mês por estudante. A pergunta inevitável é: o que é possível fazer com esse valor? Aparentemente, há uma lista de materiais que podem ser adquiridos com esse recurso financeiro, mas ela não está disponível para o público e não foi possível verificar o que inclui e a sua aplicabilidade para o uso com estudantes com AH/SD.

E, finalmente, chegamos à tentativa de impor uma Nova Política Nacional de Educação Especial, feita mediante o Decreto 10.502/2020 (BRASIL, 2020b), que felizmente teve sua eficácia suspensa pela Ação Direta de Inconstitucionalidade 6590 do Supremo Tribunal de Justiça, aprovada por maioria pelo Plenário do STJ, no dia 18 de abril de 2021 (BRASIL, 2021b). Amplamente considerada um enorme retrocesso por um grande número de entidades representativas da sociedade civil, a Política fomentava a terceirização da educação especial, o retorno às classes e escolas especiais e à ingerência das áreas da saúde na Educação, ferindo, assim, os princípios da inclusão vigentes no mundo inteiro.

\section{Considerações que não podem e nem deveriam ser finais}

Entre 1996 e 2021, os estudantes com AH/SD acompanharam as mudanças naquela que ainda continua se chamando "Nova" LDBEN embora já tenha alcançado a maioridade há muito tempo. Nos 25 anos que nos separam de sua primeira edição, os alunos "superdotados" sempre integraram o públicoalvo da Educação Especial, com diferentes nomes (superdotados, portadores de Altas Habilidades, portadores de Altas Habilidades/Superdotação, educandos com necessidades especiais). Na última nomenclatura, eles passam a ser educandos com Altas Habilidades ou Superdotação, uma disjuntiva que tem trazido grandes confusões entre a grande maioria de professores e demais pessoas que nunca tiveram formação sobre o tema.

Apesar de estar vigente e determinar o Atendimento Educacional Especializado para os estudantes com AH/SD desde suas letras iniciais, essa obrigatoriedade prevista nos Artigos 58, 59 e 60 
que, segundo a redação dada pela lei 13.632 de 2018 ao inciso $3^{\circ}$ do Artigo 58, deve "começar na educação infantil e estender-se ao longo da vida” (BRASIL, 2021a, p. 24) e que, segundo a modificação da lei 12.796 de 2013 ao item III do Artigo 4 , deve ser gratuito e "transversal a todos os níveis, etapas e modalidades de educação" (BRASIL, 2021a, p. 2) ainda está por acontecer 25 anos depois de ter sido determinada.

$\mathrm{Na}$ verdade, o que se constata na grande maioria dos documentos relacionados à Educação Especial ao longo da história da Educação do nosso país é que, se eliminássemos a substituição do termo "deficiência" por "deficiência, transtornos globais do desenvolvimento e altas habilidades/superdotação" gerada para simular a "inclusão" dos estudantes com AH/SD e deixássemos apenas “deficiência”, as leis, decretos e normas educacionais permaneceriam inalterados. Infelizmente, a associação da "Educação Especial" ao atendimento devido apenas aos estudantes com deficiência - comum na sociedade, nos meios de imprensa, nas formações docentes, entre os profissionais da saúde e os educadores assim como nas publicações acadêmicas da área - continua preservando o grande manto de invisibilidade que vulnerabiliza ainda mais as pessoas com AH/SD. Enquanto muitos acreditam que oferecer AEE aos estudantes com AH/SD seria um "elitismo", o mesmo não é entendido quando se trata do AEE para estudantes com deficiência, simplesmente porque elite significa "o que há de melhor" e o mito de acreditar que as pessoas com AH/SD são "melhores" reflete um preconceito ainda mais profundo, o de que as pessoas com deficiência não podem sê-lo.

$\mathrm{Na}$ América Latina, o Brasil continua sendo pioneiro nos textos legais e nas normas educacionais. Tomara que algum dia, possamos ver identificados, registrados no censo escolar, atendidos educacionalmente e valorizados os quase cinco milhões de estudantes brasileiros com AH/SD.

\section{REFERÊNCIAS}

BRASIL. Lei n 4024, de 20 de dezembro de 1091. Fixa as Diretrizes e Bases da Educação Nacional, Brasília, DF, Diário Oficial da União, seção 1, p. 11429, 28 dez. 1961. Disponível em: https://www.gov.br/imprensanacional/pt-br. Acesso em 22 fev. 2021.

BRASIL. Lei $n^{\circ}$ 5692, de 11 de agosto de 1971. Fixa diretrizes e bases para o ensino de $1^{\circ}$ e $2^{\circ}$ graus, e dá outras providências. Brasília, DF, Diário Oficial da União, seção 1, p. 6377, 12 ago. 1971. Disponível em: https://www.gov.br/imprensanacional/pt-br. Acesso em 22 fev. 2021.

BRASIL. Ministério da Educação. Conselho Federal de Educação. Parecer 711/87, 02 set 1987. Brasília: MEC/CFE, 1987. Disponível em: http://www.livrosgratis.com.br/ler-livro-online-58222/parecercfecomissao-especial-de-universidades-n7111987. Acesso em 12 nov. 2020.

BRASIL. Ministério da Educação e do Desporto. Secretaria de Educação Especial. Política Nacional de Educação Especial. Brasília: MEC/SEESP, 1994. Disponível em:

https://inclusaoja.files.wordpress.com/2019/09/polc3adtica-nacional-de-educacao-especial-1994.pdf. Acesso em: 23 mar. 2021. 
BRASIL. Ministério da Educação. Secretaria de Educação Especial. Diretrizes gerais para o atendimento educacional aos alunos portadores de altas habilidades/superdotação e talentos. Brasília: SEESP/MEC, 1995a.

BRASIL. Ministério da Educação. Secretaria de Educação Especial. Subsidios para organização e funcionamento de serviços de Educação Especial - Area de Altas Habilidades. Brasília: DF, 1995b.

BRASIL. Ministério da Educação. Secretaria de Educação Especial. Diretrizes nacionais para a educação especial na educação básica. 2 ed. Brasília: MEC/SEESP, 2001 a.

BRASIL Lei n 10.172, de 09 de janeiro de 2001. Aprova o Plano Nacional de Educação e dá outras providências. Brasilia, DF, Diário Oficial da União, seção 1, p. 1, 10 jan. 2001b. Disponível em: https://www.gov.br/imprensanacional/pt-br. Acesso em: 20 fev. 2021.

BRASIL. Ministério de Educação. Secretaria de Educação Especial. Politica Nacional de Educação Especial na perspectiva da Educação Inclusiva. Brasília: MEC/SEESP, 2008. Disponível em: http://portal.mec.gov.br/arquivos/pdf/politicaeducespecial.pdf. Acesso em: 26 nov. 2020.

BRASIL. Ministério da Educação. Conselho Nacional de Educação. Câmara de Educação Básica. Resolução no 4, de 2 de outubro de 2009. Institui Diretrizes Operacionais para o Atendimento Educacional Especializado na Educação Básica, modalidade Educação Especial. Brasília, DF, Diário Oficial da União, seção 1, n. 190, p. 17, 04 out. 2009. Disponível em: http://portal.mec.gov.br/dmdocuments/rceb004 09.pdf. Acesso em: 12 jan. 2021.

BRASIL. Ministério de Educação. Secretaria de Educação Especial. Manual de Orientação: Programa de Implantação de Sala de Recursos Multifuncionais. Brasília: MEC/SEESP, 2010.

BRASIL. Decreto $n^{\circ} 7611$ de 17 de novembro de 2011. Dispõe sobre a educação especial, o atendimento educacional especializado e dá outras providências. Diário Oficial da União. Edição Extra, Brasília, DF, seção 1, p. 12, 18 nov., 2011a. Disponível em: https://www.gov.br/imprensanacional/pt-br. Acesso em: 22 fev. 2021.

BRASIL. Ministério da Educação. Secretaria de Educação Continuada, Alfabetização, Diversidade e Inclusão. Diretoria de Políticas de Educação Especial. Nota Técnica $N^{o}$

46/2013/MEC/SECADI/DPEE, 22 abr. 2013. Brasília: MEC/SECADI, 2013. Disponível em: https://iparadigma.org.br/wp-content/uploads/Ed-incluisva-76.pdf. Acesso em: 31 jan. 2021.

BRASIL. Ministério da Educação. Secretaria de Educação Continuada, Alfabetização, Diversidade e Inclusão. Diretoria de Políticas de Educação Especial. Nota Técnica No 40/2015/

MEC/SECADI/DPEE, 15 jun. 2015. Brasília: MEC/SECADI, 2015a.

https://inclusaoja.files.wordpress.com/2016/05/a-consolidac3a7c3a3o-da-inclusc3a3o-escolar-nobrasil-2003-a-2016.pdf. Acesso em: 23 mar. 2021.

BRASIL. Lei n 13.234, de 29 de dezembro de 2015. Altera a Lei no 9.394, de 20 de dezembro de 1996 (Lei de Diretrizes e Bases da Educação Nacional), para dispor sobre a identificação, o cadastramento e o atendimento, na educação básica e na educação superior, de aluno. Brasília, DF, Diário Oficial da União, seção 1, p. 1, 30 dez. 2015b. Disponível em: https://www.gov.br/imprensanacional/pt-br. Acesso em: 20 fev. 2021.

BRASIL. Ministério da Educação. Fundo Nacional de Desenvolvimento da Educação. Resolução n 15 , de 7 de outubro de 2020. Brasília, DF, Diário Oficial da União, seção 1, n. 197, p. 91, 14 out. 2020a. Disponível em: https://www.gov.br/imprensanacional/pt-br. Acesso em: 20 fev. 2021.

BRASIL. Decreto n 10.502, de 30 de setembro de 2020. Institui a Política Nacional de Educação Especial: Equitativa, Inclusiva e com Aprendizado ao Longo da Vida, Brasília, DF, Diário Oficial da União, 
seção 1, n. 189, p. 6, 01 out. 2020b. Disponível em: https://www.gov.br/imprensanacional/pt-br. Acesso em: 20 fev. 2021.

BRASIL. Supremo Tribunal Federal. Ação Direta de Inconstitucionalidade 6590, de 21 dez 2020. Disponível em: http://portal.stf.jus.br/processos/detalhe.asp?incidente=6036507. Acesso em: 21 mar. $2021 \mathrm{a}$.

DUARTE, Rosa Maria Prista. Superdotados \& psicomotricidad: um resgate à unidade do ser. Petrópolis: Vozes, 1993.

GARDNER, Howard. Estructuras de la mente: la teoría de las Inteligencias Múltiples. Bogotá: Fondo de Cultura Económica, 2011.

INSTITUTO BRASILEIRO DE GEOGRAFIA E ESTATÍSTICA (IBGE) (Brasil). Nota Técnica 01/2018. Releitura dos dados de pessoas com deficiência no Censo Demográfico 2010 à luz das recomendações do Grupo de Washington, Brasília: IBGE, 2018. Disponível em:

https://ftp.ibge.gov.br/Censos/Censo_Demografico_2010/metodologia/notas_tecnicas/nota_tecnica _2018_01_censo2010.pdf. Acesso em: 10 abr. 2021.

INSTITUTO NACIONAL DE ESTUDOS E PESQUISAS EDUCACIONAIS ANÍSIO TEIXEIRA (Brasil). Sinopses estatísticas. Disponível em: https://www.gov.br/inep/pt-br/acesso-ainformacao/dados-abertos/sinopses-estatisticas. Acesso em: 06 mar. 2021.

MARLAND, Sidney. P. Junior. Education of the Gifted and Talented: Report to the Congress of the United States by the U.S. Commissioner of Education. Washington, D.C.: U.S. Department of Health, Education \& Welfare, Office of Education, v. I, 1971. Disponível em: https:// files.eric.ed.gov/fulltext/ED056243.pdf. Acesso em: 21 jan. 2021.

MÖNKS, Franz J.; KATZKO, Michael W. Giftedness and Gifted Education. In: STERNBERG, Robert; DAVIDSON, Janet E. Conceptions of giftedness. 2 ed. Cambridge: Cambridge University Press, 2005. p. 187-200.

NOVAES, Maria Helena. Desenvolvimento psicológico do superdotado. São Paulo: Atlas, 1979.

ORGANISATION DES NATIONS UNIES POUR L'ÉDUCATION, LE SCIENCE ET LA

CULTURE (UNESCO). Déclaration de Salamanque et cadre d'action pour les besoins éducatifs spéciaux.

Salamanca: UNESCO, 1994. Disponível em:

https://www.gisti.org/IMG/pdf/declarationsalamanque.pdf. Acesso em: 16 abr. 2021.

PINTO, Estêvão. O problema da educação dos bem-dotados. São Paulo: Melhoramentos, 1933.

RENZULLI, Joseph. What Makes Giftedness? Reexamining a definition. Phi Delta Kappan, v. 60, n. 3 , p. 180-184, 1978. Disponível em: https://gseuphsdlibrary.files.wordpress.com/2013/03/what-makesgiftedness.pdf. Acesso em: 21 fev. 2021.

RENZULLI, Joseph. The Three-ring conception of Giftedness: A Developmental Model for Creative Productivity. In: RENZULLI, Joseph; REIS, Sally. The Triad Reader. Mansfield Center, Connecticut: Creative Learning Press, 1986. p. 2-19. 